\section{Expression of NPAT, a novel substrate of cyclin E-CDK2, promotes S-phase entry}

\author{
Jiyong Zhao, ${ }^{1,4}$ Brian Dynlacht, $^{1,3}$ Takashi Imai, $^{2}$ \\ Tadaaki Hori, ${ }^{2}$ and Ed Harlow ${ }^{1}$
}

${ }^{1}$ Laboratory of M olecular Oncology, M assachusetts General Hospital (MGH) Cancer Center, Charlestown, M assachusetts 02129 USA; ' $\mathrm{G}$ enome Research Group, National Institute of Radiological Science, Inage-ku, Chiba 263, Japan

\begin{abstract}
To understand the mechanisms by which CDKs regulate cell cycle progression, it is necessary to identify and characterize the physiological substrates of these kinases. We have developed a screening method to identify novel CDK substrates. One of the CDNAs identified in the screen is identical to the recently isolated NPAT gene. Here we show that NPAT associates with cyclin E-CDK2 in vivo and can be phosphorylated by this CDK. The protein level of NPAT peaks at the $G_{1} / S$ boundary. Overexpression of NPAT accelerates S-phase entry, and this effect is enhanced by coexpression of cyclin ECDK2. These results suggest that NPAT is a substrate of cyclin E-CDK2 and plays a role in S-phase entry.
\end{abstract}

Received N ovember 25, 1997; revised version accepted January 7, 1998.

Progression through the eukaryotic cell cycle requires the activation of cyclin-dependent kinases (CDKs). The activities of these kinases are tightly regulated by both positive and negative factors in normal cells, and perturbation of CDK activities can result in tumorigenesis (Hunter and Pines 1994; Sherr 1996). Although the regulation of CDK activation has been studied intensively in recent years, the mechanisms by which these CDKs regulate cell cycle progression are not fully understood partly because few substrates of these kinases have been identified.

Previous studies have shown that some protein $\mathrm{ki}$ nases, including CDKs, form stable complexes with their respective substrates in vivo (Kato et al. 1993; Dynlacht et al. 1994, 1997; Krek et al. 1994; Karin and Hunter 1995; Zhu et al. 1995; Adams et al. 1996; Kallunki et al. 1996). This physical interaction has been suggested as a mechanism by which the specificity and efficiency of the kinase reactions are achieved. Thus, a possible approach for identifying substrates of a protein kinase is to search for proteins that interact physically with the kinase. We have devel oped a method to screen expression libraries for potential CDK substrates and identified a novel sub-

[Key Words: Cyclin; CDK; substrates; NPAT; S-phase entry] 3Present address: Department of Molecular and Cellular Biology, Harvard University, Cambridge, Massachusetts 02138 USA.

${ }^{4}$ Corresponding author.

E-MAIL zhao@helix.mgh.harvard.edu; FAX (617) 726-7808. strate of cycl in E-CDK2, a kinase complex that regul ates the $\mathrm{G}_{1} / \mathrm{S}$-phase transition and is required for the initiation of DNA replication in higher eukaryotes (Fang and Newport 1991; Ohtsubo and Roberts 1993; Tsai et al. 1993; Resnitzky et al. 1994).

\section{Results and Discussion}

To identify cDNAs that encode new cyclin E-CDK2interacting proteins and thus potential substrates, we screened a phage expression library by a binding assay (Fig. 1). Unlike previously reported yeast two-hybrid screens in which only CDK2 was used as the probe for interacting proteins (Hannon et al. 1993; Harper et al. 1993), we used a preparation of purified cyclin E-CDK2 complex as the probe for two reasons: (1) Active cycl in E-CDK2 complex was used, so the protein complexes could easily be labeled with [ $\gamma^{-32}$ P]ATP by the active cyclin E-CDK2; and (2) more importantly, it has been shown that cyclins are involved in determining the substrate specificity of CDKs (Peeper et al. 1993; Dynlacht et al. 1994, 1997; Krek et al. 1994; Zhu etal. 1995). Thus, the presence of cyclin $\mathrm{E}$ may be required in a screen to identify important substrates of cyclin E-CDK2 complex. The kinase-inactive CDK2 (CDK2dn) was al so used in the screen to maximize the binding to the substrates in case the kinase activity of the wild-type CDK2 weakened its binding to the substrates. From $1.2 \times 10^{6}$ clones
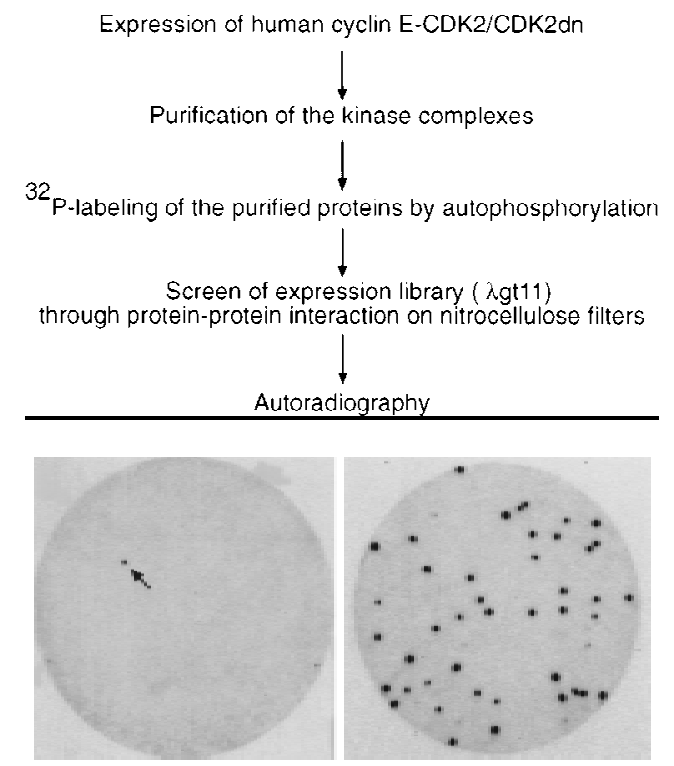

Figure 1. Binding screen for cyclin E-CDK2-interacting proteins. (Top) Outline of the binding screen (for details, see Materials and M ethods). (Bottom) A utoradi ographs showing a positive clone identified in primary (left) and tertiary (right) screens, respectively. In the primary screen, the $\lambda$ gt 11 phage library was plated at a density of $1.8 \times 10^{4} \mathrm{PFU} / 15-\mathrm{cm}$ plate. In the tertiary screen, 50-100 PFU was plated on a 10-cm plate. The arrow indicates the positive clone in the primary screen. 
NPAT: a substrate of cyclin E-CDK2

screened, we isolated 34 positive clones. Of these, 27 encode proteins that have been demonstrated previously to be associated with cycl in E-CDK2 in vivo (8 clones for p27, 1 clone for p107, 18 clones for p130) (Lees et al. 1992; Hannon et al. 1993; Li et al. 1993; Polyak et al. 1994; Toyoshma and Hunter 1994). Isolation of p27, p107, and p130 from the screen demonstrates that the method can identify authentic cyclin E-CDK2-associated proteins. The other six CDN As (one cDN A was isolated twice) encode fragments of proteins that have not been shown previously to interact with cyclin E-CDK2 in vivo. The deduced peptide sequence from one clone contained residues similar to the RRLFG motif shown previously to be involved in the interaction with cyclin A/E-CDK2 complexes (Zhu et al. 1995; Adams et al. 1996; Russo et al. 1996). Recombinant protein made from this cDNA clone bound cyclin E-CDK2, but not cyclin D1/CDK6, and could be phosphorylated by cyclin E-CDK2, but not cyclin D1/CDK4, in vitro (data not shown). Therefore, this clone was chosen for further studies. While our work was in progress, the gene was also isolated independently, under the names NPAT, E14, and CAN3, through positional cloning by virtue of the fact that the gene is located next to ATM on chromosome 11q22-q23 and may share a bidirectional promoter with ATM (Byrd et al. 1996; Imai et al. 1996; Chen et al. 1997).

The NPAT (for nuclear protein mapped to the AT Iocus) protein consists of $1 \overline{4} 27$ amino acids (Imai et al. 1996) and has an apparent molecular mass of $210 \mathrm{kD}$ when analyzed by SDS-PAGE (Fig. 2A; data not shown). To determine whether NPAT is associated with cyclin E-CDK2 in vivo, cell lysates were subjected to immunoprecipitation and Western blotting analysis using specific anti-cyclin E, anti-CDK2, and anti-N PAT antibodies. Although the proteins immunopreci pitated by a control antibody included neither cyclin E-CDK2 nor N PAT (Fig. 2), the protein complex immunoprecipitated by anti-cyclin $\mathrm{E}$ monoclonal antibody from human osteosarcoma U2OS cell lysates contai ned NPAT protein (Fig. 2A). Consistently, the amount of N PAT precipitated by anti-cyclin E antibody was increased in cells transfected with NPAT, cyclin E, and CDK2 expression plasmids (Fig 2B). In reci procal experiments, analysis of the endogenous protein complex immunoprecipitated by antiNPAT monoclonal antibody demonstrated the presence of cyclin E (Fig. 2C) and CDK2 (Fig. 2D) in the complex. The amount of cyclin E-CDK2 immunoprecipitated by the anti-N PAT antibody is comparable to that precipitated by an antibody against p21 (Fig. 2C,D), a known cyclin E-CDK2 interacting protein (Harper et al. 1993). These results confirmed physical association of NPAT with cyclin E-CDK2 in vivo. The identity of the 230-kD protein that is recognized by anti-NPAT antibody (Fig. $2 A$ ) is not clear at present, but it could be the product of a differentially spliced NPAT mRNA or the product of a related gene. Consistent with this notion, two mRNA species that hybridize to the NPAT sequence have been detected in all human adult tissues examined and in several human cell lines (Byrd et al. 1996; Imai et al. 1996;

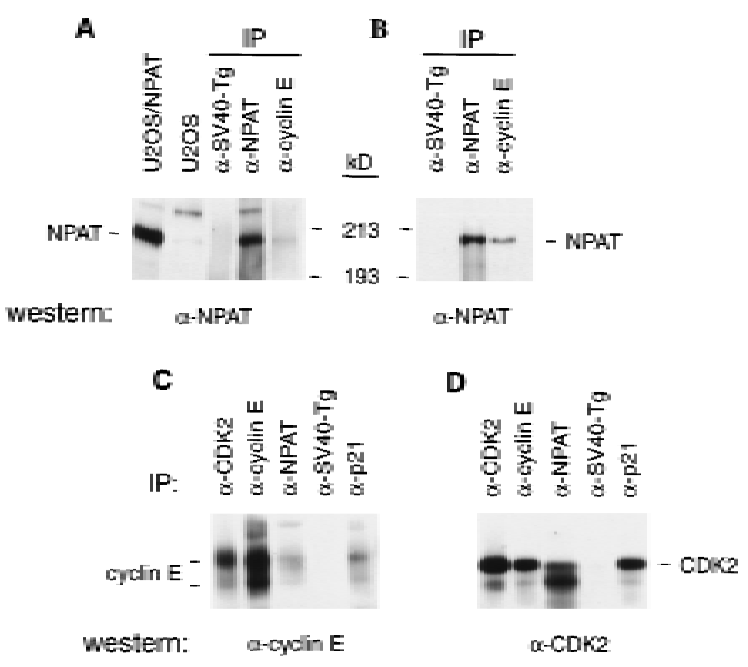

Figure 2. In vivo association of NPAT with cyclin E-CDK2. (A) Lysates (1 mg of total protein) from U2OS cells were immunoprecipitated with an anti-N PAT monoclonal antibody (DH3), anti-cyclin E antibody (HE67) or a control monoclonal antibody (anti-SV40-Tg antibody, PAB419), respectively. The immunoprecipitates were analyzed by Western blotting with a mouse anti-N PAT polyclonal antibody. The first lane was loaded with total protein $(25 \mu \mathrm{g})$ from U2OS cells transfected with pCMVNPAT, and the second lane was loaded with $50 \mu \mathrm{g}$ of total protein from U2OS cells. (B) Same as described in A except that the lysates ( $0.25 \mathrm{mg}$ of total protein) were prepared from U $20 \mathrm{~S}$ cells transfected with N PAT $(10 \mu \mathrm{g})$, cyclin E $(2.5 \mu \mathrm{g})$, and CDK2 $(2.5 \mu \mathrm{g})$ expression plasmids. (C, D) Lysates (1 mg of total protein) from U2OS cells were immunoprecipitated with indicated antibodies. The immunopreci pitates were analyzed by Western blotting with anti-cyclin E monoclonal antibody (HE12), (C) or anti-CDK2 antibody (D).

Chen et al. 1997; data not shown). The intensity of the band that migrates faster than the CDK2 band (Fig. 2D) varied greatly from experiment to experiment. The identity of the band is not clear and is currently being investigated.

To examine the protein level of N PAT throughout the cell cycle, U2OS cells were synchronized in M phase by nocodazol e treatment. The amount of NPAT in the cells at different times after rel ease from the nocodazole block was analyzed by anti-N PAT antibody. Although N PAT appears to be expressed in all phases of the cell cycle, the protein level of NPAT peaks at the $\mathrm{G}_{1} / \mathrm{S}$ boundary and decreases when cells enter $S$ phase (Fig. 3), suggesting that NPAT may play a role at the $G_{1} / S$ boundary. Consistently, NPAT protein is diminished in serum-starved or contact-inhibited normal human fibroblatst WI38 cells (data not shown).

To gain further insight into the function of NPAT, we determined the effect of NPAT overexpression on cell cycle distribution. When transfected into U2OS cells, N PAT caused a large increase in the fraction of cells in S-phase and a concomitant decrease in the $G_{1}$ population. (Fig. 4A,B). To rule out the possibility that the increase of S-phase population was due to an S phase block 


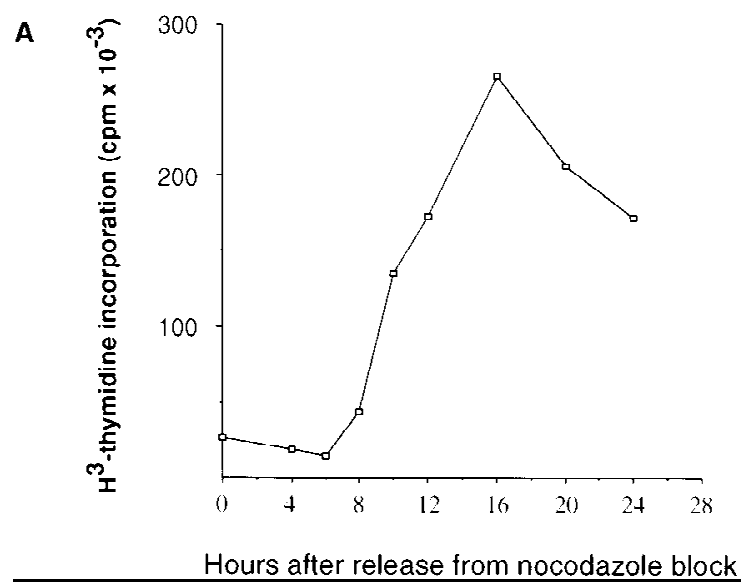

B $\begin{array}{llllllllll}0 & 4 & 6 & 8 & 10 & 12 & 16 & 20 & 24 & 28\end{array}$

NPAT CDK2

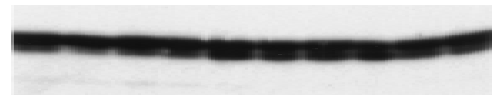

Figure 3. The level of NPAT protein peaks at the $\mathrm{G}_{1} / \mathrm{S}$ boundary. (A) DNA synthesis in U2OS cells after removal of nocodazole was monitored by $\left[{ }^{3} \mathrm{H}\right]$ thymidine incorporation. (B) Lysates ( $50 \mu \mathrm{g}$ of total protein) prepared from cells at the indicated times (hr) after rel ease from nocodazole block were analyzed by Western blotting with a rabbit anti-N PAT polyclonal antibody (top). As a control, the lysates were also subjected to Western blotting analysis with anti-CDK2 antibody (bottom).

caused by overexpression of NPAT, we used nocodazole to block cell cycle at $M$ phase and compared cell cycle distribution of NPAT-transfected cells with that of vector-transfected cells. As shown in Figure 4C, NPATtransfected cells, like vector-transfected cells, proceeded to the $M$ phase, demonstrating that the increase in S-phase population was not the result of an S-phase block. The effect of NPAT overexpression on cell cycle distribution is reminiscent of that resulting from overexpression of cyclin E or cyclin D1 in mammalian cells (Ohtsubo and Roberts 1993; Resnitzky et al. 1994). To determine whether overexpression of NPAT, like overexpression of cyclin E or cyclin D1, promotes entry into $S$ phase, we examined the changes in the distribution of cells in the cell cycle at different times after transfection with N PAT or control vector (T able 1 ). N ocodazole was added at $22 \mathrm{hr}$ after transfection to arrest cells at $M$ phase so that the relative rates at which transfected cells passing through $\mathrm{G}_{1}$ phase into $S$ phase could be measured and compared. At early times (e.g., $22 \mathrm{hr}$ ) after transfection, distribution of cells in the cell cycle was virtually identical for both NPAT - and vector-transfected cells. At later times $(25,28,31,34 \mathrm{hr})$, however, the percentage of cells in $\mathrm{S}$ phase is much higher in NPAT-transfected cells than in control vector-transfected cells. This increase in S-phase population was accompanied by a de- crease in the $G_{1}$ population of NPAT-transfected cells, whereas there was no significant change in $\mathrm{G}_{2} / \mathrm{M}$ population. These results show that overexpression of NPAT accel erates S-phase entry in U2OS cells. Taken together, these observations (Figs. 3 and 4; Table 1) suggest that NPAT may function in some step that is ratelimiting in the $G_{1} /$ S-phase transition. Although our results suggest that overexpression of N PAT results in shortening of $\mathrm{G}_{1}$ phase, it is not clear, though possible, whether $S$ phase is lengthened to compensate for the shortened $G_{1}$ when the cells are pushed into $S$ phase. We note that the effect of overexpression of N PAT on cell cycle distribution varied considerably among different cell lines (data not shown), suggesting that in addition to the expression of NPAT, other unidentified events are al so involved in the accelerated S-phase entry in these cells.

Because NPAT and cyclin E-CDK2 associate in vivo and expression of each accelerates S-phase entry, we examined the effect of coexpression of NPAT and cyclin E-CDK2 on the cell cycle distribution. Coexpression of NPAT and cyclin E-CDK2 together has a cooperative effect on the increase in S-phase population (Fig. 4D), whereas coexpression of NPAT with cyclin A-CDK2 or with cycl in D1-CDK4 does not have this effect (data not shown), indicating that NPAT and cyclin E-CDK2 are not only associated physically but rel ated functional ly as well.

The observation that NPAT interacts physically and functionally with cyclin E-CDK2 in vivo and that recombinant NPAT can be phosphorylated by purified cyclin E-CDK2 in vitro (data not shown) prompted us to examine whether NPAT complexed with cyclin ECDK2 in cells can be phosphorylated by this kinase in vitro. Cell lysates were immunoprecipitated with anticyclin $E$ antibody, and the immunocomplexes were incubated with $\left[\gamma-{ }^{32} \mathrm{P}\right]$ ATP. As shown in Figure 5A, both endogenous and transfected NPAT in anti-cyclin E immunoprecipitations were phosphorylated. The fact that phosphorylation of NPAT is inhibited by purified p21 protein and that the phosphorylation of transfected NPAT is diminished when a kinase-inactive CDK2 is cotransfected (Fig. 5A) indicates that phosphorylation of NPAT in the anti-cyclin E immunoprecipitations depends on active cyclin E-CDK2 in the complex. To determine whether N PAT can be phosphorylated by cyclin E-CDK2 in vivo, we examined phosphorylation of NPAT in cells transfected with NPAT alone or together with cyclin E-CDK2 expression constructs. NPAT was phosphorylated at basal level in U2OS cells when transfected alone (Fig. 5B). When coexpressed with active cyclin E-CDK2, phosphorylation of N PAT was greatly increased. In contrast, coexpression of a kinase-inactive CDK2 with cyclin E did not increase the phosphorylation of NPAT. Increased phosphorylation of NPAT by cyclin E-CDK2 is not merely a consequence of accelerated S-phase entry, as overexpression of cyclin D1/ CDK4, which also promotes S-phase entry (data not shown), did not result in increased phosphorylation of NPAT (Fig. 5B). These results suggest that NPAT is a substrate of cyclin E-CDK2 in human cells and that the 
A

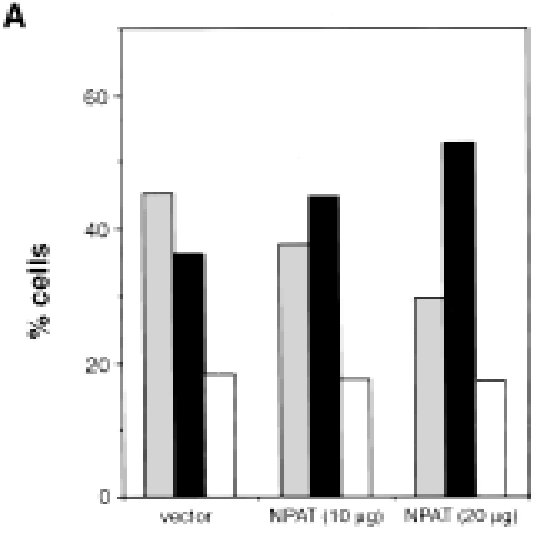

C

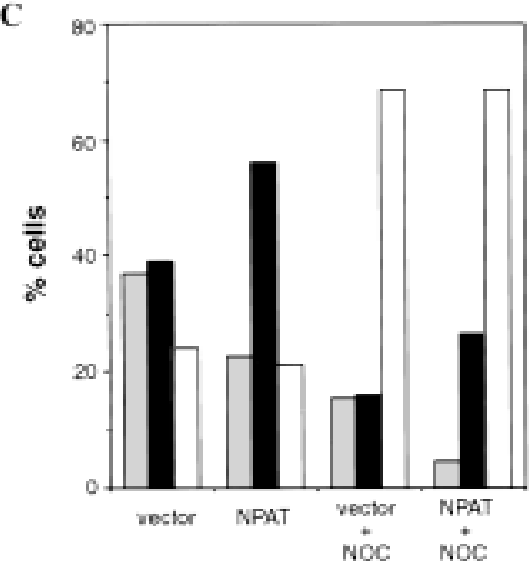

B

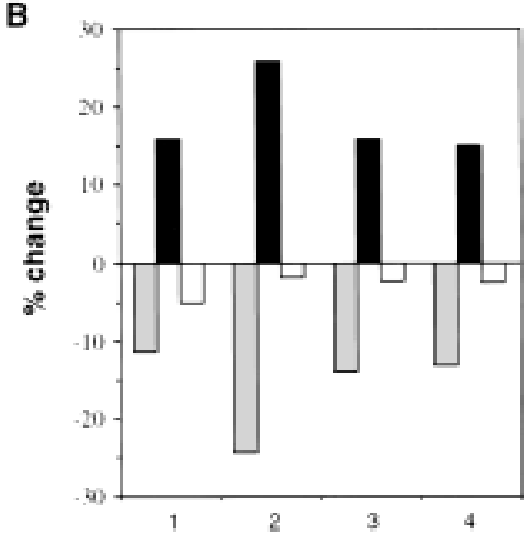

D

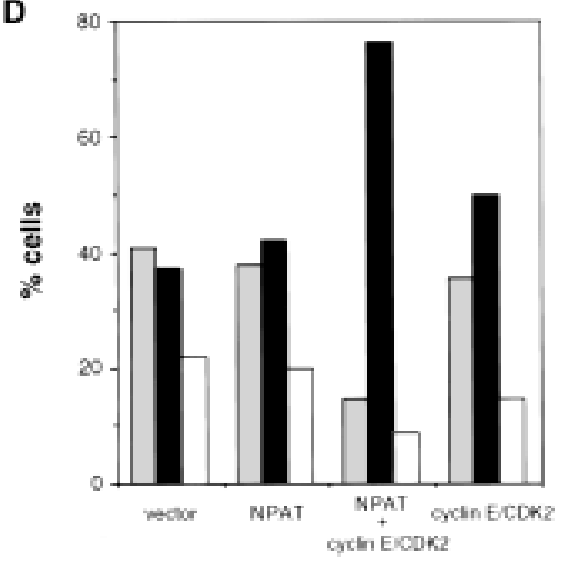

Figure 4. Effects of overexpression of NPAT on U2OS cell cycle distribution. (A) cells were transfected with control $\mathrm{pCMV}$ vector al one or with indicated amounts of $\mathrm{PCMV}$ NPAT, and were analyzed by FACS. The results represent the means from triplicate samples. (B) Cells were transfected with $20 \mu \mathrm{g}$ of vector or $20 \mu \mathrm{g}$ of pCMV-NPAT and analyzed as in A. The absolute percentage differences between N PAT-transfected cells and vector-transfected cells (\% N PAT-transfected cells-\% vector-transfected cells) were calculated. The mean results from duplicate samples in four independent experiments (1-4) are depicted. (C) Cells were transfected with $20 \mu \mathrm{g}$ of vector or PCM V-N PAT in the presence (vector +NOC; NPAT +NOC) or absence of nocodazole and were analyzed as in A. Shown are the mean results from duplicate samples; similar results have al so been obtained in four other independent experiments. (D) Cells were transfected with the indicated expression plasmids (10 $\mu \mathrm{g}$ of NPAT; $2.5 \mu \mathrm{g}$ of cyclin E; and $2.5 \mu \mathrm{g}$ of CDK2) and analyzed as in A. The mean results from duplicate samples are presented. ( $\square$ ) $G_{1}$ phase; ( $\square$ ) S phase; $(\square) G_{2} / M$ phase.

cooperative effect of coexpression of NPAT and cyclin E-CDK2 on the cell cycle distribution (Fig. 4D) may result from the phosphorylation of NPAT by the cyclin E-CDK2 complex. Because cotransfection of N PAT with cyclin A/CDK2 did not show the cooperative effect on the cell cycle progression and the recombinant GST fusion protein encoded by the original isolated NPAT cDNA did not bind cyclin A/CDK2 in vitro (data not shown), we did not investigate further whether N PAT is associated with cyclin A/CDK2 in vivo or whether it is also a substrate of this kinase complex.

Identification of cyclin E-CDK2 substrates is crucial for elucidating the mechanism by which this kinase regulates the $\mathrm{G}_{1}$ /S-phase transition and initiation of DN A replication. Several cell cycle-related proteins have

\section{Materials and methods}

Preparation of ${ }^{32} \mathrm{P}-$ labeled human cyclin E-CDK2/cyclin E-CDK2dn Expression and purification of human cyclin E-CDK2 and cyclin ECDK2dn from recombinant baculoviruses in insect cells were carried out as described previously (Dynlacht et al. 1994). To label the protein complexes, purified cyclin E-CDK2 and cyclin E-CDK2dn were mixed and incubated in the presence of $\left[\gamma-{ }^{32} \mathrm{P}\right] \mathrm{ATP}$ at $30^{\circ} \mathrm{C}$ for $30-60 \mathrm{~min}$. The unincorporated free $\left[\gamma_{-}{ }^{32} \mathrm{P}\right] \mathrm{ATP}$ was removed from the labeled proteins using a Centricon 10 (Amicon). The specificities of Iabeled protein complexes were $5 \times 10^{6}-1 \times 10^{7} \mathrm{cpm} / \mu \mathrm{g}$ of protein.

Binding screen of phage expression library

A $\lambda$ gt 11 cDN A library prepared from human T-cell leukemia M olt- 4 cells (Clontech) was screened. Phage plating, incubation, and protein transfer were performed essentially as suggested by the manufacturer based on the method described by Y oung and Davis (1983). After protein transfer, the filters were blocked in 5\% milk in PBS with $0.5 \mathrm{~mm}$ PMSF, $0.2 \mathrm{~mm}$ benzamindine $-\mathrm{HCl}$ at $4{ }^{\circ} \mathrm{C}$ overnight. The blocked filters were incubated 
Table 1. Overexpression of NPAT in U 20 S cells accel erates S-phase entry

\begin{tabular}{|c|c|c|c|c|c|c|c|c|c|c|c|c|c|c|}
\hline & \multicolumn{2}{|c|}{$22 \mathrm{hr}$} & \multicolumn{2}{|c|}{$25 \mathrm{hr}$} & \multicolumn{2}{|c|}{$28 \mathrm{hr}$} & \multicolumn{2}{|c|}{$31 \mathrm{hr}$} & \multicolumn{2}{|c|}{$34 \mathrm{hr}$} & \multicolumn{2}{|c|}{$36 \mathrm{hr}$} & \multicolumn{2}{|c|}{$46 \mathrm{hr}$} \\
\hline & vector & NPAT & vector & NPAT & vector & NPAT & vector & NPAT & vector & NPAT & vector & NPAT & vector & NPAT \\
\hline $\mathrm{G}_{1}(\%)$ & 62.9 & 60.8 & 57.4 & 48.3 & 43.6 & 31.5 & 35.7 & 17.5 & 29.6 & 11.6 & 34.8 & 12.6 & 27.7 & 9.9 \\
\hline $\mathrm{S}(\%)$ & 31.0 & 31.1 & 32.8 & 41.9 & 44.2 & 56.8 & 47.0 & 64.9 & 35.4 & 54.9 & 30.2 & 44.3 & 16.7 & 23.5 \\
\hline $\mathrm{G}_{2} \mathrm{M}(\%)$ & 6.1 & 8.1 & 9.8 & 9.8 & 12.2 & 11.7 & 17.3 & 17.6 & 35.0 & 33.5 & 35.0 & 43.1 & 55.6 & 66.6 \\
\hline
\end{tabular}

U2OS cells were transfected with pCM V-neo (vector) or PCM V-N PAT. N ocodazole $(75 \mathrm{ng} / \mathrm{ml}$ ) was added to the culture medium at 22 hr post-transfection. Cells were harvested at the indicated times post-transfection, and the distribution of transfected cells in the cell cycle was analyzed by FACS. The data representing the mean results from two independent experiments deviated $<3 \%$ from each other.

with the labeled protein probes at a concentration of $0.12-0.2 \mu \mathrm{g}$ of protein/ $\mathrm{ml}$ of binding solution $[25 \mathrm{~mm}$ Tris- $\mathrm{HCl}$ at $\mathrm{pH} 7.5,100 \mathrm{~mm} \mathrm{KCl}, 5$ $\mathrm{mm} \mathrm{MgCl}, 1 \mathrm{~mm}$ DTT, $0.1 \%$ Tween 20,5\% glycerol, $1 \%$ milk, $10 \mathrm{~mm}$ $\mathrm{NaF}, 0.1 \mathrm{~mm} \mathrm{Na} \mathrm{VO}_{4}, 0.4 \mathrm{~mm}$ AEBSF (Calbiochem), $0.2 \mathrm{~mm}$ benzamidine $\mathrm{HCl}, 1 \mu \mathrm{g} / \mathrm{ml}$ each of leupeptin and aprotinin] at room temperature for 1-3 hr. Filters were then washed four times for $15 \mathrm{~min}$ each in a washing solution $(25 \mathrm{~mm}$ Tris- $\mathrm{HCl}$ at $\mathrm{pH} 7.5,100 \mathrm{~mm} \mathrm{KCl}, 5 \mathrm{~mm} \mathrm{M} \mathrm{gCl}$, $0.1 \mathrm{~mm}$ DTT, $0.1 \%$ Tween 20,5\% glycerol, $0.1 \mathrm{~mm} \mathrm{Na} \mathrm{VO}_{4}, 1 \mathrm{~mm} \mathrm{NaF}$, $0.2 \mathrm{~mm}$ PMSF, $0.2 \mathrm{~mm}$ benzamidine-HCl). Washed filters were air-dried and exposed to X-ray films at $80^{\circ} \mathrm{C}$ for $4-20 \mathrm{hr}$.

Antibodies, Western blotting, and immunoprecipitation Anti-CDK2 antibody (M2) was from Santa Cruz. Anti-cyclin E (HE12, HE67) antibodies, anti-p21 antibody (CP68), and anti-HA antibody
A

B
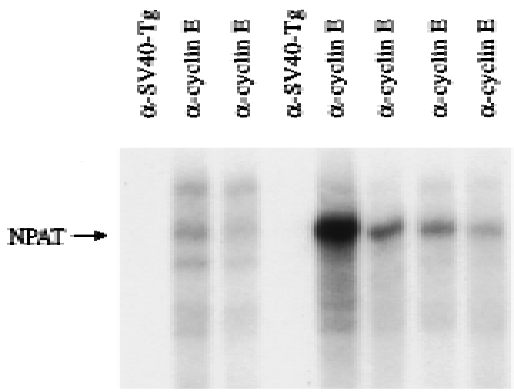

$\begin{array}{ccccccccc}\text { CDK2 } & - & - & - & + & + & - & + & - \\ \text { NPAT } & - & - & - & + & + & + & + & + \\ \text { grclin E } & - & - & - & + & + & + & + & - \\ \text { CDK2di } & - & - & - & - & - & + & - & - \\ \text { p2L } & - & - & + & - & - & - & + & -\end{array}$
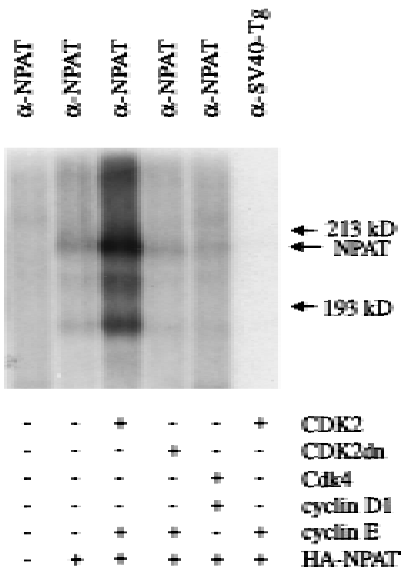

Figure 5. Phosphorylation of NPAT by cyclin E-CDK2. (A) Lysates from U2OS cells ( $1 \mathrm{mg}$ of total protein) or from U2OS cells $(0.25 \mathrm{mg}$ of total protein) transfected with plasmids expressing indicated proteins were pre cipitated with anti-cyclin E (HE 67) or a control antibody (pAb 419) as indicated. The immunoprecipitates were incubated with $\left[\gamma^{32}\right.$ p]ATP in the absence $(-)$ or presence $(+)$ of purified CDK inhibitor p21 protein $(20 \mathrm{ng})$ as indicated. The phosphorylation of NPAT was determined by reimmunoprecipitation of the phosphorylated protein with anti-N PAT antibody (DH3). The amounts of expression plasmids used in the transfection experiments were $15 \mu \mathrm{g}$ of NPAT, $4 \mu \mathrm{g}$ of cyclin E, and $6 \mu \mathrm{g}$ of CDK2 and CDK2dn, re spectively. (B) U2OS cells were transfected with indicated expression plasmids, and the cellular phosphoproteins were label ed with $\left[{ }^{32} \mathrm{P}\right]$ orthophosphate. Lysates were immunoprecipitated with anti-NPAT antibody (DH3) or a control antibody as indicated. The immunoprecipitates were denatured and reimmunoprecipitated with anti-HA antibody (12CA5). Fifteen micrograms of HA-tagged NPAT, $4 \mu \mathrm{g}$ of cyclin E, $6 \mu \mathrm{g}$ of CDK2/CDK2dn, $4 \mu \mathrm{g}$ of cyclin D1, and $6 \mu \mathrm{g}$ of CDK4 expression plasmids were used in the transfection experiments.
(12CA5) have been described previously (Zhu et al. 1995). Mouse antiNPAT polyclonal and monoclonal antibodies were prepared according ino acids 782-1081 of NPAT as the immunogen. Rabbit anti-N PAT protein G-Sepharose beads as described (Harlow and Lane 1988). Immunoprecipitation and Western blot analysis were performed according to $5 \%$ glycerol, $0.4 \mathrm{~mm}$ AEBSF, $0.5 \mathrm{~mm}$ benzamidine $\mathrm{HCl}, 5 \mu \mathrm{g} / \mathrm{ml}$ of leu$\mathrm{a}_{3} \mathrm{VO}_{4}$, and $50 \mathrm{~mm} \beta$-glycerophosphate.

\section{Expression plasmids}

The cyclin D, cyclin E, CDK2, and CDK2dn and the vector (pCMVneo) plasmids have been described previously (Hinds et al. 1992; van den Heuvel and Harlow 1993). The N PAT expression plasmid (pCMV-N PAT) was made by cloning the full-length NPAT CDNA sequence including both $5^{\prime}$ and $3^{\prime}$ noncoding sequence (Imai et al. 1996) into the pCMV-neo vector at the BamHI site. The HA-tagged N PAT was made by PCR. A 10-amino-acid epitope tag (YPYDVPDYAS) was inserted at the amino terminus of the protein. The sequence of the PCR product was verified by DN A sequencing. The DN A sequence encoding HA-tagged NPAT was cloned into the pCMV-neo vector.

Transient transfection and FACS analysis

Transient transfection and FACS analysis were performed essentially as described previously (van den Heuvel and Harlow 1993). Unless otherwise stated, cells were cultured in DMEM supplemented with $10 \%$ FBS. Transfections were done on 100-mm dishes using indicated plasmid DNA, together with pCMV-CD 20 plasmid for the selection of transfected cells. Cells were harvested at $40-48 \mathrm{hr}$ after transfection or as indicated. In the experiments described in Figure 4C, nocodazole $(70 \mathrm{ng} / \mathrm{ml}$ ) was added to half of the samples at $26 \mathrm{hr}$ after transfection and the cells were harvested for analysis 22 hr later.

\section{Cell cycle synchronization}

U $20 S$ cells were incubated with nocodazole $(75 \mathrm{ng} / \mathrm{ml})$ for 22 hr in DMEM supplemented with $10 \%$ FBS. Then, the cells were washed twice with PBS and incubated in the fresh medium without nocodazole.

$\left[{ }^{3} \mathrm{H}\right]$ thymidine incorporation

U2OS cells rel eased from nocodazole block were incubated at a concentration of $5 \times 10^{5}$ cells/60-mm dish in DMEM with $10 \% \mathrm{FBS}$. At the indicated times $10 \mu \mathrm{Ci}$ of $\left[{ }^{3} \mathrm{H}\right]$ thymidine was added to $3 \mathrm{ml}$ of culture medium. After $1 \mathrm{hr}$, cells were washed with PBS and lysed with $0.3 \mathrm{~N} \mathrm{NaOH}$. DNA was precipitated with TCA $(10 \%)$, and incorporation of $\left[{ }^{3} \mathrm{H}\right]$ thymidine into DNA was determined by liquid scintillation counting.

Phosphorylation assay of immunoprecipitates

Following immunoprecipitation with indicated antibodies, 
the immunoprecipitates were incubated with or without p21 in $50 \mu$ of kinase buffer (50 mM HEPES at pH 7.0, $10 \mathrm{~mm} \mathrm{M} \mathrm{gCl}, 4 \mathrm{~mm} \mathrm{MnCl}, 1 \mathrm{~mm}$ DTT, $0.1 \mathrm{~mm} \mathrm{BSA}, 2 \mu \mathrm{Ci}$ of $\left.\left[\gamma_{-}^{-32} \mathrm{P}\right] \mathrm{ATP}\right)$ at $30^{\circ} \mathrm{C}$ for $30 \mathrm{~min}$. The reaction was terminated with SDS-PAGE loading buffer. The mixtures were diluted 20 -fold with $2 \%$ BSA in PBS and reimmunoprecipitated with antiNPAT monoclonal antibody (DH3). The immunoprecipitates were analyzed by autoradiography following SDS-PAGE. Recombinant human p21 protein was purified as described (Zhu et al. 1995).

\section{In vivo [ $\left.{ }^{32} \mathrm{P}\right]$ phosphate labeling}

U2OS cells were transfected with indicated plasmids. Thirty-two hours after transfection, the cells were washed twice with phosphate-free DMEM and incubated in phosphate-free DMEM for $1 \mathrm{hr}$. Then the cells were incubated in phosphate-free DMEM containing $0.5 \mathrm{mCi} / \mathrm{ml}$ of [ ${ }^{32} \mathrm{P}$ ] orthophosphate (ICN) for $4 \mathrm{hr}$. The lysates were immunopreci pitated and analyzed by autoradiography following SDS-PAGE.

\section{Acknowledgments}

We are grateful to Drs. Marie Classon, Brian Kennedy, Nick Dyson, and Hubert Chou for critical reading of the manuscript and suggestions. We thank Dr. Jim Koh for technical help, Chidi N gwu for help with preparation of anti-NPAT monoclonal antibodies, David Dombkowski for assistance with flow cytometry analysis, Dr. Joshua LaBaer for suggestions, and members of M olecular Oncology Laboratory and M GH Cancer Center for stimulating discussions. This study was supported by an American Cancer Society postdoctoral fellowship to J.Z., a Damon Runyon postdoctoral fellowship to B.D., and grants from the $\mathrm{N}$ ational Institutes of Health to E.H.

The publication costs of this article were defrayed in part by payment of page charges. This article must therefore be hereby marked "advertisement" in accordance with 18 USC section 1734 solely to indicate this fact.

\section{References}

Adams, P.D., W.R. Sellers, S.K. Sharma, A.D. Wu, C.M. N alin, and W.G. Kaelin. 1996. Identification of a cyclin-cdk2 recognition motif present in substrates and p21-like cyclin-dependent kinase inhibitors. Mol. Cell. Biol. 16: 6623-6633.

Byrd, P.J., P.R. Cooper, T. Stankovic, H.S. Kullar, G.D. Watts, P.J. Robinson, and M.R. Taylor. 1996. A gene transcribed from the bidirectional ATM promoter coding for a serine rich protein: Amino acid sequence, structure and expression studies. Hum. Mol. Genet. 5: 1785-1791.

Chen, X., L. Yang, N. U dar, T. Liang, N. Uhrhammer, S. Xu, J-O. Bay, X. Wang, S. Dandakar, S. Chiplunkar, I. Klisak, M. Telatar, H. Yang, P. Concannon, and R. Gatti. 1997. CAND3: A ubiquitously expressed gene immediately adjacent and in opposite transcriptonal orientation to the ATM gene at 11q23.1. Mamm. Genome 8: 129-133.

Dynlacht, B.D., O. Flores, J.A. Lees, and E. Harlow. 1994. Differential regulation of E2F trans-activation by cyclin-cdk2 complexes. Genes \& Dev. 8: 1772-1786.

Dynlacht, B.D., K. Moberg, J.A. Lees, E. Harlow, and L. Zhu. 1997. Spe cific regulation of E2F family members by cyclin-dependent kinase. Mol. Cell. Biol. 17: 3867-3875.

Fang, F. and J.W. Newport. 1991. Evidence that the G1-S and G2-M transitions are controlled by different cdc2 proteins in higher eukaryotes. Cell 66: 731-742.

Fruscio, M.D., H. Weiger, B.C. Vanderhyden, T. Imai, T. Shiomi, T.-A. Hori, R. Jaenisch, and D.A. Gray. 1997. Proviral inactivation of the $\mathrm{N}$ pat gene of $\mathrm{Mpv} 20$ mice results in early embryonic arrest. Mol. Cell. Biol. 17: 4080-4086.

Hannon, G.J., D. Demetrick, and D. Beach. 1993. Isolation of the Rbrelated p130 through its interaction with CDK2 and cyclins. Genes \& Dev. 7: 2378-2391.

Harlow, E. and D. Lane. 1988. Antibodies: A laboratory manual. Cold Spring Harbor Laboratory, Cold Spring Harbor, NY.

Harper, J.W., G.R. Adami, N. Wei, K. Keyomarsi, and S.J. Elledge. 1993. The p21 Cdk-interacting protein Cip1 is a potent inhibitor of G1 cyclin-dependent kinases. Cell 75: 805-816.

Herrera, R.E., F. Chen, and R.A. Weinberg. 1996. Increased histone H1 phosphorylation and relaxed chromatin structure in $\mathrm{Rb}$-deficient fibroblasts. Proc. Natl. Acad. Sci. 93: 11510-11515.
Hinds, P.W., S. Mittnacht, V. Dulic, A. Arnold, S.I. Reed, and R.A. Weinberg. 1992. Regulation of retinoblastoma protein functions by ectopic expression of human cyclins. Cell 70: 993-1006.

Hunter, T. and J. Pines. 1994. Cyclins and cancer II: Cyclin D and cdk inhibitors come of age. Cell 79: 573-582.

Imai, T., M. Yamauchi, N. Seki, T. Sugawara, T. Saito, Y. M atsuda, H. Ito, T. Nagase, N. Nomura, and T. Hori. 1996. Identification and characterization of a new gene physically linked to the ATM gene. Genome Res. 6: 439-447.

Kallunki, T., T. Deng, M. Hibi, and M. Karin. 1996. c-Jun can recruit JN K to phosphorylate dimerization pateners via specific docking interactions. Cell 87: 929-939.

Karin, M. and T. Hunter. 1995. Transcriptional control by protein phosphorylation: Signal transmission from the cell surface to the nucleus. Curr. Biol. 5: 747-757.

Kato, J., H. Matsushime, S.W. Hiebert, M.E. Ewen, and C.J. Sherr. 1993. Direct binding of cyclin $D$ to the retinoblastoma gene product $(p R b)$ and $\mathrm{pRb}$ phosphorylation by the cyclin D-dependent kinase CDK4. Genes \& Dev. 7: 331-342.

Krek, W., M. Ewen, S. Shirodkar, Z. Arany, W.G. Kaelin, and D. Livingston. 1994. Negative regulation of the growth-promoting transcription factor E2F-1 by a stably bound cyclin A-dependent protein kinase. Cell 78: 161-172.

Lees, E., B. Faha, V. Dulic, S.I. Reed, and E. Harlow. 1992. Cyclin E/cdk2 and cyclin A/cdk2 kinases associate with p107 and E2F in a temporally distinct manner. Genes \& Dev. 6: 1874-1885.

Li, Y., C. Graham, S. Lacy, A.M. Duncan, and P. Whyte. 1993. The adenovirus E1A-associated 130-kD protein is encoded by a member of the retinoblastoma gene family and physically interacts with cyclins A and E. Genes \& Dev. 7: 2366-2377.

Ohtsubo, M. and J.M. Roberts. 1993. Cyclin-dependent regulation of G1 in mammalian fibroblasts. Science 259: 1908-1912.

Peeper, D.S., L.L. Parker, M.E. Ewen, M. Toebes, F.L. Hall, M. Xu, A. Zantema, A.J. van der Eb, and H. Piwnica-Worms. 1993. A- and Btype cyclins differentially modulate substrate specificity of cyclincdk complexes. EMBO J. 12: 1947-1954.

Polyak, K., M.-H. Lee, H. Erdjument-Bromage, A. Koff, J.M. Roberts, P. Tempst, and J. Massague. 1994. Cloning of p2 $7^{\mathrm{Kip1}}$, a cyclin-dependent kinase inhibitor and a potential mediator of extracellular antimitogenic signals. Cell 78: 59-66.

Resnitzky, D., M. Gossen, H. Bujard, and S.I. Reed. 1994. Acceleration of the $\mathrm{G} 1 / \mathrm{S}$ phase transition by expression of cyclins D1 and $\mathrm{E}$ with an inducible system. Mol. Cell. Biol. 14: 1669-1679.

Russo, A.A., P.D. Jeffrey, A.K. Patten, J. Massague, and N .P. Pavletich. 1996. Crystal structure of the p27Kip1 cyclin-dependent-kinase inhibitor bound to the cyclin A-Cdk2 complex. Nature 382: 325-331.

Sheaff, R.J., M. Groudine, M. Gordon, J.M. Roberts, and B.E. Clurman. 1997. Cyclin E-CDK2 is a regulator of $\mathrm{p} 27^{\mathrm{kip} 1}$. Genes \& Dev. 11: $1464-1478$.

Sherr, C.J. 1996. Cancer cell cycles. Science 274: 1672-1677.

Toyoshima, H. and T. Hunter. 1994. p27, a novel inhibitor of G1 cyclinCdk protein kinase activity, is related to p21. Cell 78: 67-74.

Tsai, L.-H., E. Lees, B. Faha, E. Harlow, and K. Riabowol. 1993. The cdk2 kinase is required for the G1-to-S transition in mammalian cells. Oncogene 8: 1593-1602.

van den Heuvel, S. and E. Harlow. 1993. Distinct roles for cyclin-dependent kinases in cell cycle control. Science 262: 2050-2054.

Young, R.A. and R.W. Davis. 1983. Efficient isolation of genes using antibody probes. Proc. Natl. Acad. Sci. 80: 1194-1198.

Zhu, L., E. Harlow, and B.D. Dynlacht. 1995. p107 uses a p21 ${ }^{\text {CIP1-related }}$ domain to bind cyclin/cdk2 and regulate interactions with E2F. Genes \& Dev. 9: 1740-1752. 


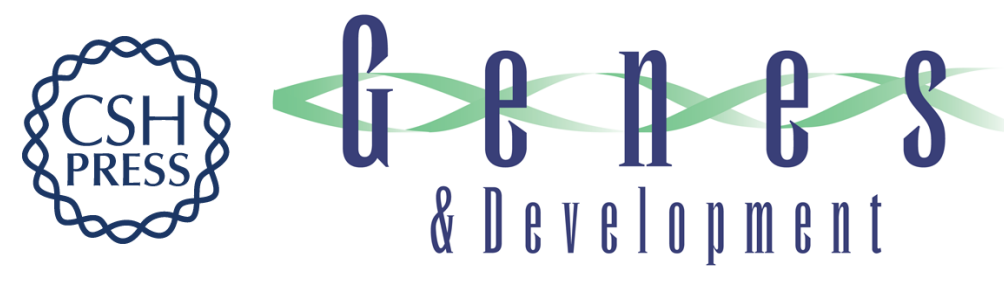

\section{Expression of NPAT, a novel substrate of cyclin E-CDK2, promotes S-phase entry}

Jiyong Zhao, Brian Dynlacht, Takashi Imai, et al.

Genes Dev. 1998, 12:

References This article cites 31 articles, 17 of which can be accessed free at: http://genesdev.cshlp.org/content/12/4/456.full.html\#ref-list-1

License

Email Alerting

Receive free email alerts when new articles cite this article - sign up in the box at the top Service right corner of the article or click here.

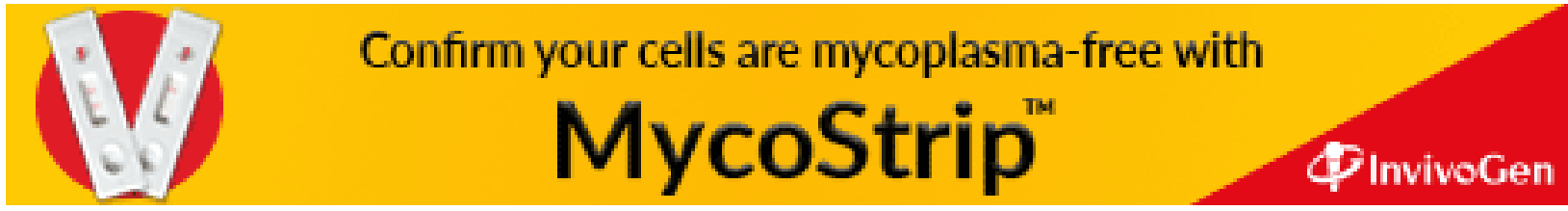

